\title{
Optimal Design of a Small Permanent Magnet Wind Generator for Rectified Loads
}

\author{
Jawad Faiz ${ }^{1, *}$, Nariman Zareh $^{1}$ \\ ${ }^{1}$ Center of Excellence on Applied Electromagnetic Systems, School of Electrical and Computer Engineering, \\ University of Tehran, Tehran, Iran \\ *Corresponding author. Tel: +98 61114223, Fax: +98 88533029, E-mail: jfaiz@ut.ac.ir
}

\begin{abstract}
This paper presents an optimal design procedure for a small permanent magnet wind generator which supplies a full-bridge diode rectified load. The aim is to improve the output voltage waveform of the generator. An electromagnetic-thermal design algorithm is proposed based on an analytical model of a surface-mounted permanent magnet generator. A comprehensive combined model, consisting of design program and simulation of the designed generator under rectified load, is utilized. Design variables are optimized over their appropriate limits using a genetic algorithm. The results indicate the improvement of the output voltage waveform.
\end{abstract}

Keywords: Wind Generator, Permanent Magnet Machine, Optimal Design

\section{Nomenclature}

U rated wind velocity..................m/s $\quad D$

$U_{\text {mean }} \quad$ dominant mean velocity of wind.. $\mathrm{m} / \mathrm{s}$

$\beta \quad$ pitch angle.............................rad.

$R \quad$ blade radius............................. $K_{w}$

$\omega_{r} \quad$ shaft angular speed.................rad/s $C$

$C_{p}(\lambda, \beta) \quad$ turbine aerodynamic efficiency....\% $K_{c}$

$\eta_{g e n} \quad$ efficiency of generator...............\% $p_{r l}$

$P_{g e n} \quad$ rated output electrical power ........W $\quad K_{s}$

$n_{s} \quad$ rotation speed.......................pm $\tau_{s}$

$S M L_{p k} \quad$ peak specific magnetic loading......T THD

$\mathrm{SEL}_{\mathrm{pk}} \quad$ specific electric loading...........A/m $\quad K$

$h_{s y}, h_{r y} \quad$ stator and rotor yoke height..........m $\lambda\left(\omega_{r} R / U\right)$

$w_{s} \quad$ stator slot width $\left(\tau_{s^{-}} \mu_{r}\right.$ $\left.w_{t}\right) \ldots \ldots \ldots \ldots \ldots . . . . m$ air gap diameter..........................m

stator, rotor saturated flux density... T pole numbers

winding factor

flux conical factor

carter coefficient

normalized rotor leakage peamability

stator lamination factor

stator slot pitch $(\pi D / S)$

voltage time harmonic distortion

shape parameter

tip speed ratio

relative permeability

\section{Introduction}

Permanent magnet generator (PMG) is a self-excited system and it can be a proper choice to coupling it to wind turbine. The output of the generator can charge the batteries or supply inverter or both [1]. There are different techniques to connect a DC bus (with power electronics devices) to the PMG [2]. Utilization of rectified loads distorts the output voltage waveform of the PMG leading to a low quality power delivered to the load. A proper operation of the generator under such conditions requires a precise design optimization of the PMG. Such design needs an appropriate modeling and comprehensive design algorithm.

Details of PMG design for direct coupling to a wind turbine has been given in [3] in which four configurations including radial-flux, axial-flux, cross-field-flux and claw-pole generators have been compared based on the air gap flux density, copper losses, PM weakening and the system cost. This comparison indicates that a radial-flux, internal-PM is a proper choice for designing a $400 \mathrm{~kW}$ generator. Application of different configurations of PMG for wind turbine has been proposed in [4] and $60 \mathrm{c}$ onfigurations has been compared based on the torque density and also cost per developed torque function. It shows a radial-flux PMG using surface-mounted Ferrite PMs has a better performance compared with the internal PM 
version. In [5], the axial-flux and radial-flux PMGs, for direct driven wind turbine, have been optimized based on the cost per developed torque objective function. The results indicate that the radial-flux machines have lower cost and torque density. In [6], two types of radial-flux PMG (internal- and surface-mounted PM) with inner rotor structures for direct coupling to wind turbine are analyzed and compared. The electromagnetic behavior of generators and optimal shape of the PMs have been estimated by finite element method (FEM). The results indicate lower torque ripples in the surface-mounted PMG. Design and performance analysis of an ironless axial-flux PMG have been proposed in [7] and [8]. The particular ironless machine configuration leads to a longer effective air gap of the machine. Also a multi-variable optimization algorithm based on the design parameters for improvement of the PMG performance of the machine has been introduced. Finally, a prototype $3.5 \mathrm{~kW}$ machine has been built and tested in which noise, cogging torque and copper losses have been reduced in expense of heavier machine. In [9], a small radial- and axial-flux wind generators have been optimally designed using an optimization algorithm based on population growth which tries to maximize annual energy gaining from variable speed wind turbine-generator. However, thermal analysis of the PMG has been neglected.

In recent years application of power electronics components in variable speed drives and controlling output of generators has been increased. Therefore, a reliable, economical design and satisfactory operation of these machines are crucial. This paper considers the electromechanical conversion of wind energy. Electromagnetic design procedure of a surfacemounted radial-flux PMG and its thermal model are proposed. A comprehensive combined model consisting of the generator design routine and simultaneous simulation of the typical design in the presence of a rectified load is introduced and impact of this type of load upon the distortion of the output voltage waveform of the generator is studied. Finally, the design optimization procedure is proposed to achieve a near sinusoidal output voltage waveform.

\section{Electromechanical Conversion of Wind Energy}

Wind speed is modeled as a continuous stochastic variable. The probability of the occurrence of a define wind velocity can be expressed by a probability density function. Comparisons of the measured wind speeds show that if the time interval is long enough, the Weibull distribution function is suitable to describe the wind velocity $[10,11]$ :

$$
f(U)=\frac{k}{C}\left(\frac{U}{C}\right)^{k-1} e^{-\left(\frac{U}{c}\right)^{k}}
$$

where $\mathrm{k}=2$ and $\mathrm{c}$ is the magnification parameter $\left(2 U_{\text {mean }} / \sqrt{ } \pi\right)$. A portion of the wind energy transmitted to the shaft is converted into mechanical energy by blades of the turbine and its efficiency depends on the blades profile, and air density. Wind energy converted into mechanical energy $\left(P_{\text {shaft }}\right)$ is:

$$
P_{\text {shaft }}=0.5 \rho_{\text {air }} \pi R^{2} U^{3}\left(0.51\left(\frac{116}{\lambda_{1}}-0.4 \beta-5\right) e^{-\frac{21}{\lambda_{1}}}+0.006 \lambda\right)
$$

Nowadays most horizontal three-blade turbines are designed as such that their operating point are placed in the range of 5 to $7 \mathrm{~m} / \mathrm{s}$. In this case, turbine operates with maximum $C_{p}(\lambda, \beta)$ between 0.35 and 0.45 [9]. $R$ and $\omega_{r}$ can be determined as follows:

$$
\begin{aligned}
& R=\sqrt{\frac{P_{\text {gen }}}{\frac{1}{2} \rho_{\text {air }} \pi U^{3} C_{P} \eta_{\text {gen }}}} \\
& \omega_{r}=\sqrt{\frac{\frac{1}{2} \rho_{\text {air }} \pi \lambda^{2} U^{5} C_{P} \eta_{\text {gen }}}{P_{\text {gen }}}}
\end{aligned}
$$


Eqns. (3) and (4) can be used as a guide for estimation of $R$ and $U$ in the design process of the small wind generator.

\section{Design of PMG}

Low-Carbon soft-steel is used in the rotor and silicon-steel laminations in the stator of PMG. The slot has semi-closed shape. The PM $(\mathrm{NdFeB})$ pieces are mounted on the external surface of the rotor. The apparent power of the air gap of a radial-flux generator $\left(S_{g}\right)$ versus the main dimensions of the machine is as follows [12]:

$$
S_{g}=\frac{1}{2} \pi^{2} \cdot K_{w 1} \cdot D^{2} L \cdot n_{s} \cdot S M L_{p k} \cdot S E L_{p k}
$$

Product $\mathrm{D}^{2} \mathrm{~L}$ determines the capability of the energy absorbed by the turbine:

$$
D^{2} L=\frac{\varepsilon P_{g e n}}{0.5 \pi^{2} \cdot K_{w 1} \cdot n_{s} \cdot S M L_{p k} \cdot S E L_{p k} \cdot \cos \varphi}
$$

where $\varepsilon=E_{f} / V_{a}$. Ratio $K_{L}=L / \mathrm{D}$ is chosen in the range of 0.14 and 0.50 based on the main design and available backgrounds [12-14]. Therefore, diameter and stack length are evaluated using this ratio. In choosing $D$ a particular attention must be paid to the required $P$ and a proper pole pitch. On the other hand, in order to reduce the overhang copper losses and its additional expense, $D$ must be limited as possible.

\subsection{Magnetic Design}

The generator pole numbers, PM dimensions, stator and rotor dimensions are determined in this stage.

Air gap Flux Density: The air gap flux density is limited by saturation level of the stator teeth. An appropriate value for $S M L_{p k}$ is $0.9 \mathrm{~T}$. This can hold a relative balance between the magnetic circuit saturation and power absorption capability of PMG $[15,16]$.

Generator Poles Number: Frequency range of small PMGs is between 10 and $70 \mathrm{~Hz}$ or 30 and $80 \mathrm{~Hz}$ [9]. Therefore, the rated frequency of the generator can be chosen in the range of 45-65 Hz and $\mathrm{P}$ is then calculated. Conventional PM machines have normally low $\mathrm{P}$ and the pole pitch is considerably larger than the PM pitch; therefore, the pole arc to PM arc ratio $(\alpha)$ is not so crucial. However, in wind PMG, $\mathrm{P}$ is high and pole pitch and $\mathrm{PM}$ pitch are comparable and suggested range is between 0.67 and 0.77 [14].

PM Dimensions: Operating point of the magnetic circuit can be determined by intersection of the PM demagnetization curve and load line of the magnetic circuit. The slope of the load line shows the resistance of the PM against demagnetizing. A security margin in a surfacemounted PMG is guaranteed by choosing PC $\geq 6$. The PM length is estimated as follows [13]:

$$
l_{m}=\left(P C-p_{r l} \mu_{r}\right) \cdot C_{\phi} K_{c} l_{g}
$$

$p_{r l}$ is typically between 0.05 and 0.2 [15]. As seen, the required length of PM for providing the excitation flux depends on the air gap length. The air gap length in this design is taken to be about $0.01 D$.

Dimensions of Stator and Rotor: To prevent the saturation of the PMG yoke, a special attention must be paid to the dimensions and cross-section of the yoke. Assume a define stack length for PMG; the height of the yoke is evaluated as follows [17]: 


$$
\begin{aligned}
& h_{s y}>\frac{\alpha \pi D}{4 p K_{s}} \cdot \frac{B_{g}}{B_{s a t-s}} \\
& h_{r y}>\frac{\alpha \pi\left(D-2 l_{m)}\right.}{4 p} \cdot \frac{B_{g}}{B_{s a t-r}}
\end{aligned}
$$

In order to be ensuring about non-saturated teeth of the stator, the following constraint must be held [17]:

$$
w_{t}>\frac{\tau_{s}}{K_{s}} \cdot \frac{B_{g}}{B_{s a t-s}}
$$

In most electrical machines $w_{s}$ is taken to be almost equal to the tooth width as such that $0.5<w_{s} / \tau_{s}<0.6$ [18]. However, if $w_{s}=w_{t}=0.5 \tau_{s}$, the product of the electric and magnet loading approaches its peak value, and this maximizes the power absorption capability of PMG. Therefore, in a PMG with equal slot and tooth width, the non-saturation condition is as follows:

$B_{g}<\frac{1}{2} \cdot K_{s} \cdot B_{\text {sat }-s}$

\subsection{Electrical Design}

$S E L_{p \mathrm{k}}$ of a PMG is limited by the slot filling factor, slot height and stator conductors current density. The typical range of $S E L_{p \mathrm{k}}$ for a PMG is 1000 to $4000 \mathrm{~A} / \mathrm{m}$ [9]. For low-voltage PMGs, the slot filling factor is in the range of 0.3 and 0.5 and current density of the stator conductors is between 3 and $8 \mathrm{~A} / \mathrm{mm}^{2}$. Of course, for higher current density up to $10 \mathrm{~A} / \mathrm{mm}^{2}$, class $\mathrm{F}$ insulation for windings and a proper cooling system are suggested [16]. For given $S E L_{p \mathrm{k}}$, filling factor and conductor current density in a radial PMG with elliptic slots, the slot height is as follows [9]:

$h_{s}=\frac{S E L_{p k}}{\sqrt{2} \cdot J \cdot K_{s f} \cdot\left(1-w_{t} / \tau_{s}\right)}$

\subsection{Thermal Modeling of PMG}

Thermal analysis of any electrical machine is a crucial stage of the design process. Different models, depending on the required precision and complexity, have been so far proposed for thermal analysis of the PM machines. Here, an equivalent thermal-resistance network is used [18] to estimate the temperature distribution over 8 di fferent points of PMG. To use the model, the corresponding losses of any node are calculated and by applying the losses to the resistance network, the temperature rise of the above-mentioned points are evaluated. A particular attention must be paid to the temperature rise of the PM and winding in PMG. Conducting resistance between any two-node is used to complete the 8 poi nts in the equivalent thermal model of the motor as seen in Fig. 1. Computation procedure for the resistances is complicated and it is necessary to take into account the precise heat flow, heat convection, internal heat generation sources, different materials and dimensions of the PMG. To simplify the model, heat transfer between the PMG and cooling environment is considered assuming a mean temperature for the cooling material (15 degrees).

Two nodes have been assigned to the stator, one node to the yoke and one node to the tooth. In the full-load PMG, windings are the main source of the generated heat. Two nodes are considered in the model, one for the conductors in the slots and one for the end windings. Prediction of the PMs temperature rise is important in the thermal modeling of the PMG, 
therefore one node is assigned to the PMs. Estimation of the temperature rise of PMG by $n+1$ thermal networks need to solve $\mathrm{n}$ related equations. These equations are extracted from $\theta=G^{-1} P_{d}$ [18], where $P_{d}$ is the dissipated losses vector corresponding to any node and $\theta$ is the temperature rise vector. Thermal resistances model for forming the thermal conduction matrix $\mathrm{G}$ is as follows:

$$
G=\left[\begin{array}{ccccc}
\sum_{i=1}^{n} \frac{1}{R_{1, i}} & -\frac{1}{R_{1,2}} & & -\frac{1}{R_{1, n}} \\
-\frac{1}{R_{2,1}} & \sum_{i=1}^{n} \frac{1}{R_{2, i}} & & -\frac{1}{R_{2, n}} \\
\vdots & \vdots & \ddots & \vdots \\
-\frac{1}{R_{n, 1}} & -\frac{1}{R_{n, 2}} & & \ldots & \sum_{i=1}^{n} \frac{1}{R_{n, i}}
\end{array}\right]
$$

This model is used in the final stage of the electromagnetic design of PMG temperature constraints are maximum permissible temperature of winding $=120^{\circ} \mathrm{C}$, and $\mathrm{PM}=100^{\circ} \mathrm{C}$. If these constraints are satisfied, the design will be completed; otherwise the design process returns to the initial stage of the design routine and necessary modifications for the current density and magnetic flux density are made in order to decrease the heat and thus losses.

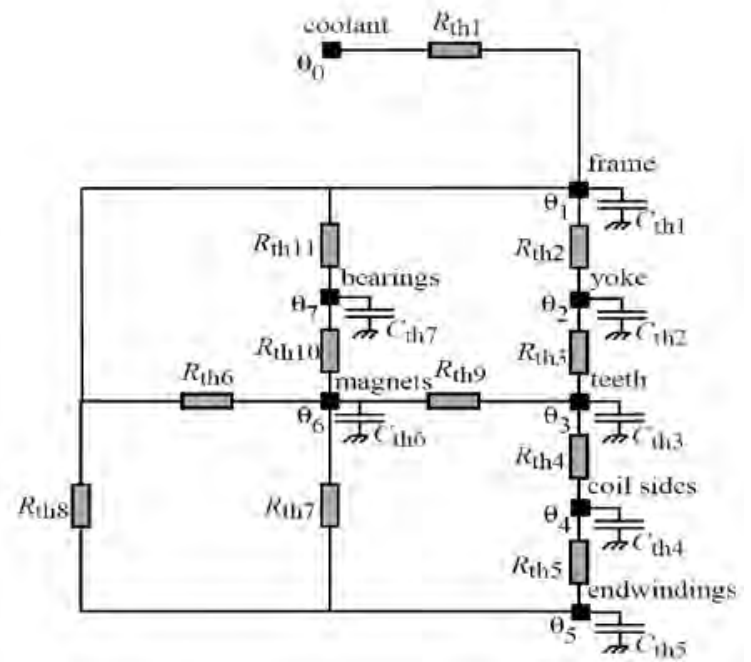

Fig. 1. Equivalent circuit of thermal model of PMG [18]

\subsection{Cost Estimation for PMG Manufacturing}

The cost of manufacturing a machine in an industrial plant is under influence of many factors such as identical built machines every year, technology and automation level used, organizing the product process, expense of the skilled labor, and quality of materials used. Since, here it is not possible to take into account all the above-mentioned factors in a mathematical model for cost estimation, a logical procedure is followed and the active materials of the machine are considered to evaluate the cost index and express it as a function of the dimensions of the PMG. The active materials of a PMG consist of PM, copper and iron used in the rotor and stator. Therefore, the cost index of a PMG is approximated as follows:

$$
C_{\text {total }}=C_{P M} \cdot \rho_{P M} \cdot V_{P M}+C_{c u} \cdot \rho_{c u} \cdot V_{c u}+C_{f e} \cdot \rho_{f e} \cdot V_{f e}
$$

where $\rho$ is the density, $V$ is the volume and $C$ is the unit weight cost of the materials. The cost of each material includes: Iron $1.65 €$, PM $50 €$ and Copper $3.1 €$. 


\subsection{Synthetic Simulation Model}

To study the impact of a rectified load upon the PMG operation, a synthetic comprehensive system consisting of simultaneous generator design routine and simulation has been proposed and applied. In this system, first the design routine calculates characteristics of the generator based on the proposed voltage, power, power factor and frequency; then turbine-generatorrectifier set included in Simulink receives the required data such as flux-linkage under each pole, resistance, inductance and poles number. At the end of simulation process, voltage waveform and performance characteristics of generator are determined. In this system, generator design algorithm is programmed. At the end of design routine, system model consisting of turbine, generator and rectifier system are implemented.

A $3 \mathrm{~kW}, 220 \mathrm{~V}, 50 \mathrm{~Hz}$ optimally designed PMG based on efficiency [9] is re-designed here in the presence of a nominal rectified load. The generator voltage waveform has been presented in Fig. 2. The results show that the harmonic distortion index of the voltage waveform is $15.5 \%$ which indicates the low quality output power of the PMG.

\subsection{Optimization}

As shown in Fig. 2, rectified load distorts the output voltage waveform and a genetic algorithm is implemented to improve the output voltage waveform. For this a fitness function based on the $\mathrm{THD}_{\mathrm{v}}$ reduction is defined as follows:

Fitness Function $=\frac{1}{T H D_{v}}$

Test designs on the wind PMG are obtained and the corresponding fitness functions are evaluated, then new design is generated by combining the best previous results. The PM residual flux density, ratio between the stack length and air gap diameter, PM arc, number of slot per pole per phase, magnetic permeance coefficient, specific electrical loading and current density are taken as design variables.

Also the range of variables values has been restricted to reasonable limits as shown in Table 1 . Fig. 3 shows the obtained voltage waveforms based on the objective function of (15). Table 2 summarizes the design details of two generators. Referring to the obtained results in the design with optimal voltage, THD of voltage improves $9 \%$. The induced voltage is Ldi/dt, and THD can be reduced by decreasing the number of winding turns.

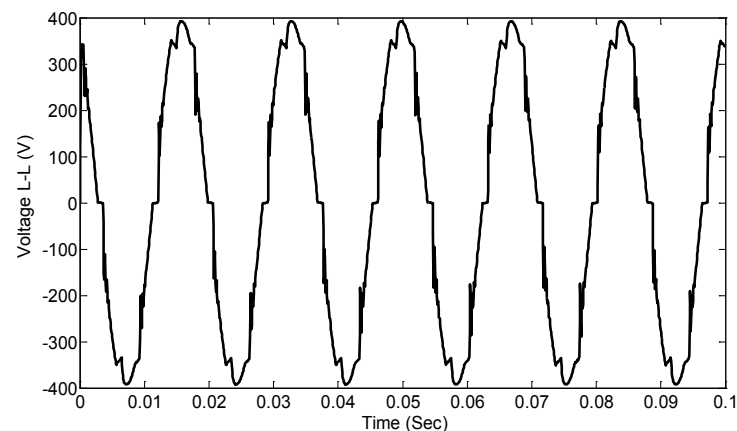

Fig. 2. Non-optimal induced line voltage of a generator under rectified load

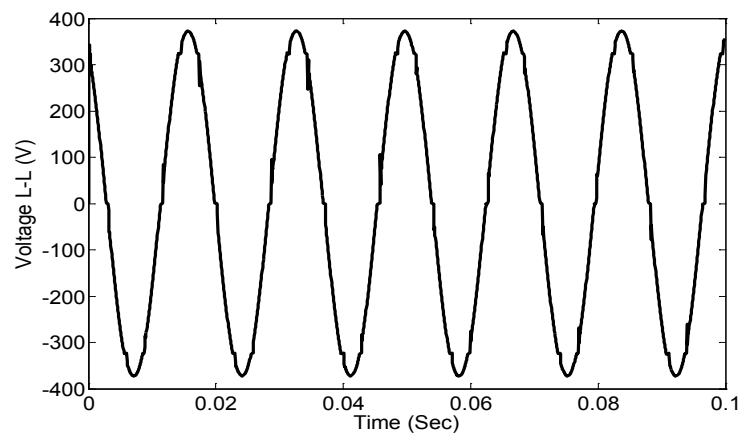

Fig. 3. Optimal induced line voltage of generator under rectified load

Also contribution of the PM arc in the pole of PMG rises in order to compensate the backemf. Following these improvements, voltage distortion is reduced, but considering the increase $S E L$ and $S M L$, the magnetic loading is decreased to provide the required power. Consequents of these changes are: rising the iron losses due to the increase of the air gap flux 
density, increasing the cost due to increase of PM volume, decreasing copper losses due to lower number of winding turns and resistance. Since the losses distribution in the optimal design of the PMG is subject to the change of the temperature rise of the six above-mentioned points, the PMG are in the permissible ranges

Table 1. Constraints of variables in optimization routine.

\begin{tabular}{lll}
\hline Parameter & Symbol & Value \\
\hline PM residual density $(\mathrm{T})$ & $\mathrm{B}_{\mathrm{r}}$ & $1-1.4$ \\
$\mathrm{PM}$ arc $\left({ }^{\circ} \mathrm{Elec}\right)$ & $\mathrm{A}$ & $90-170$ \\
Current density $\left(\mathrm{A} / \mathrm{mm}^{2}\right)$ & $\mathrm{J}$ & $3-8$ \\
Specific electrical loading $(\mathrm{kA} / \mathrm{m})$ & $\mathrm{SEL}$ & $10-40$ \\
Air gap width to diameter ratio & $\mathrm{k}_{\mathrm{L}}$ & $0.2-1$ \\
Slot No./pole/phase & $\mathrm{Q}$ & $1-2$ \\
Magnetic permeance coefficient & $\mathrm{PC}$ & $5-16$ \\
\hline
\end{tabular}

Table 2. Comparison of design and performance of a $3 \mathrm{~kW}, 220 \mathrm{~V}$ and $60 \mathrm{~Hz} P M G$ with optimal efficiency and voltage in presence of rectified load $(U=12 \mathrm{~m} / \mathrm{s})$.

\begin{tabular}{cccc}
\hline Parameter & Symbol & Optimal Efficiency & Optimal Voltage \\
\hline Shaft speed (rpm) & $\mathrm{N}_{\mathrm{m}}$ & $440 / 66$ & $440 / 66$ \\
Generator stack length $(\mathrm{m})$ & $\mathrm{L}$ & 0.1437 & 0.164 \\
Air gap diameter $(\mathrm{m})$ & $\mathrm{D}$ & 0.1437 & 0.232 \\
PM arc (elec. Deg.) & $\mathrm{A}$ & 144 & 157.5 \\
PM height (m) & $l_{\mathrm{m}}$ & 0.01 & 0.0183 \\
PM residual flux density $(\mathrm{T})$ & $\mathrm{B}_{\mathrm{s}}$ & 1.2 & 1.25 \\
Phase winding no. of turns & $\mathrm{N}_{\mathrm{ph}}$ & $\mathrm{N}_{\mathrm{ph}}$ & 176 \\
No. of slots/phase/pole & $\mathrm{q}$ & 1 & 2 \\
Air gap length $(\mathrm{m})$ & $\mathrm{l}_{\mathrm{g}}$ & 0.0011 & 0.0012 \\
Winding diameter $(\mathrm{m})$ & $\mathrm{D}_{\mathrm{cond}}$ & 0.0011 & 0.0013 \\
Copper losses/Iron losses $(\mathrm{W})$ & $\mathrm{P}_{\mathrm{cu}} / \mathrm{P}_{\mathrm{fe}}$ & $95.9 / 80.8$ & $56.5 / 136.6$ \\
Power factor & $\mathrm{Pf}$ & 91 & 93 \\
Efficiency $(\%)$ & $\eta$ & 94.18 & 93.1 \\
Air gap flux density $(\mathrm{T})$ & $\mathrm{B}_{\mathrm{g}}$ & 0.72 & 0.79 \\
Specific electric loading $(\mathrm{kA} / \mathrm{m})$ & $\mathrm{SEL}^{2}$ & 30 & 10 \\
Winding current density $\left(\mathrm{A} / \mathrm{mm}{ }^{2}\right)$ & $\mathrm{J}$ & 5 & 3.64 \\
THDv $(\%)$ & ----- & 15.5 & 5.7 \\
Materials cost $(€)$ & $\mathrm{Cost}$ & 249.9 & 776.4 \\
Stator winding resistance $(\Omega)$ & $\mathrm{R}_{\mathrm{s}}$ & 2.55 & 1.27 \\
Stator winding leakage inductance $(\mathrm{H})$ & $\mathrm{L}_{\mathrm{l}}$ & 0.003 & 0.00064 \\
Stator winding mutual inductance $(\mathrm{H})$ & $\mathrm{L}_{\mathrm{m}}$ & 0.005 & 0.0011 \\
\hline
\end{tabular}

\section{Conclusion}

In this paper a comprehensive electromagnetic-thermal design algorithm for a wind PMG was presented. A combined model consisting of simultaneous generator design program and simulation in the presence of a rectified load was used to study the impact of this type of load upon the induced voltage distortion. Base on the presented model and genetic algorithm optimization routine, specifications of an optimal generator for improvement of the induced output voltage waveform of the PMG were obtained which leads to $9 \%$ decrease of the harmonic distortion index.

\section{References}


[1] L. Hansen, F. Blaabjerg, Conceptual survey of Generators and Power Electronics for Wind Turbines, Riso National Laboratory Report, December 2001.

[2] .Baroudi, V.Dinavahi, A.Knight, A Review of Power Converter topologies for Wind Generators, IEEE Conference on Renewable Energies, Canada, Sep. 2005.

[3] E. Spooner, A.C. Williamson, Direct-coupled, Permanent-magnet Generators for Wind Turbine Applications, IEE Proc. B, Electr. Power Appl., Vol. 143, pp. 1-8, Jan. 1996.

[4] M.R. Dubois, H. Polinder, J.A. Ferreira, Comparison of Generator Topologies for Directdrive Wind Turbines, ICEM 92, pp. 761-765, Manchester, UK, 1992.

[5] M.R. Dubois, H. Polinder, J.A. Ferreira, Axial and Radial-Flux Permanent Magnet Generators for Direct-Drive Wind Turbines, EWEC, Copenhagen, Denmark, 2001.

[6] S. A. Papathanassiou, A. G. Kladas, M. P. Papadopoulos, Direct-Coupled Permanent Magnet Wind Turbine Design Considerations, European Wind Energy Conference (EWEC'99), Nice, France, 1999.

[7] N.F. Lombard, Design and Evaluation of an Ironless Stator Axial Flux PM Machine, M. Eng. Thesis, University of Stellenbosch, Matieland, South Africa, 1997.

[8] N. F. Lombard, M. J. Kamper, Analysis and Performance of an Ironless Stator Axial Flux PM Machine, IEEE Trans. Energy Conversion, Vol. 14, pp.1051-1056, Dec. 1999.

[9] M.A.Khan, Contributions to Permanent Magnet Wind Generator Design Including the Application of Soft Magnetic Composites, PhD. Thesis, University of Cape Town, 2006.

[10] M. R. Patel, Wind and Solar Power Systems, CRC Press,1999.

[11] Andreas Petersson, Analysis, Modeling and Control of Doubly-Fed Induction Generators for Wind Turbines, Ph.D. Dissertation, Chalmers University of Technology, 2005.

[12] M.A.Khan, P.Pillay, Design of a PM Wind, Optimized for Energy Capture over a Wide Operating Range, IEEE Conference on Electrical Machines and Drives, Spain, 2005.

[13] P. Lampola, J. Perho, Electromagnetic Analysis of a Low-Speed Permanent-Magnet Wind Generator, IEE Opportunity and Advances in International Power Generation Conf., pp. 55-58, 1996.

[14] N. Bianchi and A. Lorenzoni, Permanent Magnet Generators for Wind Power Industry: An Overall Comparison with Traditional Generators, IEE Opportunity and Advances in International Power Generation Conf., pp.49-54, 1996.

[15] T. J. E. Miller, Brushless Permanent-Magnet and Reluctance Motor Drives, New York: Oxford University Press, 1989.

[16] G. R. Slemon, Design of Permanent Magnet AC Motors for Variable Speed Drives, Tutorial Course of IEEE-IAS Annual Meeting, Michigan: IEEE, 1991.

[17] S. Huang, J. Luo, F. Leonardi, and T. A. Lipo, A General Approach to Sizing and Power Density Equations for Comparison of Electrical Machines, IEEE Trans. Ind. Applications, vol. 34, pp. 92-97, Jan. / Feb. 1998.

[18] J. Lindstrom, Thermal Model of a P ermanent-Magnet Motor for a Hybrid Electric Vehicle, Ph.D. Thesis, Dept. of Electric Power Engineering, Chalmers University of Technology, Sweden, 1999. 